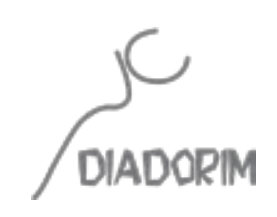

\title{
GRAFIAS EM METAMORFOSE
}

\author{
Rafael Santana ${ }^{1}$
}

\section{RESUMO}

Trata-se de uma reflexão sobre os processos da escrita em três artistas hiper-significativos no panorama da poesia portuguesa do século XX, a saber: Jorge de Sena, Carlos de Oliveira e Fiama Hasse Pais Brandão. Pensando os seus veios escriturais quer ética quer esteticamente a partir do compromisso social e da autonomia da linguagem, este artigo perscruta a poética do testemunho de Jorge de Sena em seu gesto cosmográfico, a poética da brevidade de Carlos de Oliveira em sua expressão cartográfica e a metáfora depurada de Fiama Brandão em sua manifestação gráfica.

PALAVRAS-CHAVE: Jorge de Sena; Carlos de Oliveira; Fiama Hasse Pais Brandão.

\begin{abstract}
It is about a reflection on the processes of writing in three hyper-dimension artists in the Portuguese poetry overview of the twentieth century, namely: Jorge de Sena, Carlos de Oliveira and Fiama Hasse Pais Brandão. Taking into account the social commitment and the autonomy of language in their writings, it is possible to obtain a poetics of Jorge de Sena's testimony in his cosmographic gesture, a poetics of the brevity of Carlos de Oliveira in his cartographic expression and refined metaphor by Fiama Brandão in her graphic manifestation.
\end{abstract}

KEYWORDS: Jorge de Sena; Carlos de Oliveira; Fiama Hasse Pais Brandão.

1 Professor de Literatura Portuguesa na Universidade Federal do Rio de Janeiro. E-mail: emailrafaelsantana@gmail.com.

Diadorim, Rio de Janeiro, vol. 20, n. 1, p, 81-88, jan-jun. 2018. 
Em O grau zero da escrita (1953), Roland Barthes, questionando-se a respeito de determinados parâmetros norteadores da crítica marxista mais ortodoxa, lança então aquilo que já começava a delinear-se como o cerne da sua compreensão do literário, direcionado para os fatores internos da língua e da linguagem: "A escritura é um modo de pensar a literatura, não de entendê-la", sinaliza. Recusando o lugar da exegese extraliterária em prol da liberdade da construção de sentidos possíveis através da materialidade do texto, Barthes é no entanto consciente de que a textualidade, como produto do mundo, e, mais que isso, como produção no mundo, está inexoravelmente atada à cultura de um tempo porque - diz ele com grande perspicácia “não existe literatura sem uma moral da linguagem" (2000, p.120).

Se, como quer o ensaísta francês, a escritura é "[...] a linguagem literária transformada por sua destinação social", ela (a escritura) estará sempre ligada às grandes crises da História. Afinal, como nos ensina Octavio Paz, "todo período de crise se inicia ou coincide com uma crítica da linguagem" (2012, p.37). Entre o compromisso social e a autonomia da linguagem também está atravessada toda a poesia mais significativa do século XX português e, mesmo em tempos em que a arte se quis antes de tudo espelho de si própria, a perspectiva ética fincada no desejo de ler e de escrever Portugal não se apagou daquela literatura que manifestara a preocupação de auto-afirmar-se esteticamente como um artifício de linguagem e de assinalar a aguda consciência do texto como um construto de palavras. Falo evidentemente da geração de Orpheu e de suas propostas estéticas que não poucas vezes servirão de baliza para futuros poetas, porque tais propostas se tornariam não só um lugar de contemplação e de reflexão mas sobretudo um ponto de ultrapassagem pelo gesto da metamorfose.

Jorge de Sena, em seu já revisitadíssimo prefácio (1960) a Poesia I (1961), mais do que negar o fingimento pessoano para afirmar no lugar dele a sua poética do testemunho, exercita antes uma tentativa de compreender a poética do fingimento para além dos simples termos de oposição, terminando por acentuar que o fingimento foi "a mais alta forma de educação, de libertação e esclarecimento do espírito enquanto educador de si próprio e dos outros" (1977, p.26). Na base do testemunho seniano, a poética do fingimento surge como um ponto fundamental de reflexão, como "uma lição e um exemplo" (1977, p.25) a assimilar e a ultrapassar. Porque, "num país em que ser-se poeta é ser-se um profissional do sentimento oportuno" (Ibidem ) - palavras do próprio Jorge de Sena - o fingimento pessoano vale como um ensinamento, modo de romper com todo um lirismo romântico de cariz confessional. Recusando também ele o entendimento da poesia como confissão, Sena compreende-a, antes de mais, como linguagem. Não exatamente como uma linguagem do artifício esteticista ou da autorreferencialidade - como era o caso declarado de Pessoa -, mas sim como uma linguagem que, preocupada em dizer o mundo, seria capaz de transformá-lo através da palavra do poeta que, justamente por estar no mundo e nele ter os seus olhos criticamente postos, poderia testemunhá-lo.

Perpassada pelo compromisso ético e estético está toda a poesia de Jorge de Sena, inclusive muito antes de que ele um dia viesse a postular o seu lugar na literatura como um poeta do 
testemunho. Exercitando agora o ensinamento barthesiano de ler a escritura ulterior no texto anterior, quero propor uma breve leitura do poema "Os trabalhos e os dias", de 1942, que integra o conjunto de textos que Sena publicou no ano de 1946 sob o título de Coroa da terra, vindo ainda a recuperar este volume de versos em 1961, aquando da publicação de Poesia I.

\section{OS TRABALHOS E OS DIAS}

Sento-me à mesa como se a mesa fosse o mundo inteiro e principio a escrever como se escrever fosse respirar o amor que não se esvai enquanto os corpos sabem de um caminho sem nada para o regresso da vida.

À medida que escrevo, vou ficando espantado com a convicção que a mínima coisa põe em não ser nada. Na mínima coisa que sou, pôde a poesia ser hábito. Vem, teimosa, com a alegria de eu ficar alegre, quando fico triste por serem palavras já ditas estas que vêm, lembradas, doutros poemas velhos.

Uma corrente me prende à mesa em que os homens comem. E os convivas que chegam intencionalmente sorriem e só eu sei porque principiei a escrever no princípio do mundo e desenhei uma rena para a caçar melhor e falo da verdade, essa iguaria rara: este papel, esta mesa, eu apreendendo o que escrevo. (1977, p.24)

Em clara intertextualidade com a obra de Hesíodo, Jorge de Sena escreve o seu poema que alinhava também ele os conceitos de trabalho e de justiça. Mas se em Hesíodo o trabalho agrícola é simbolicamente a demanda pelo métron por parte de uma humanidade que, incauta, desafiara o poderio dos deuses que, por sua vez, castigaram a sua hybris regalando-lhe Pandora - presente (doros) de todos (pan) -, aquela que privou o mundo da beleza do cosmos colocando os homens frente à angústia do caos, o trabalho empreendido por Jorge de Sena é antes de tudo uma reflexão sobre a palavra ou, se quisermos, uma cosmologia da palavra. "Sento-me à mesa como se a mesa fosse o mundo inteiro / e principio a escrever como se escrever fosse respirar", eis os versos iniciais destes Os trabalhos e os dias do poeta ulterior, escritura que se tece em processo de metamorfose do texto anterior.

"No princípio era o verbo", dizem as escrituras sagradas, e porque consciente de que o trabalho com a palavra é o sopro outro capaz de dar vida a corpos de linguagem, esse poeta declaradamente interessado em testemunhar tudo aquilo que é próprio do humano transita ao longo de sua obra por domínios mais que vastos, que vão do macrocosmo ao microcosmo. Compondo uma arte poética que abarca o cotidiano aparentemente mais trivial - "Na mínima 
coisa que sou, pôde a poesia ser hábito" - e ao mesmo tempo um saber intelectual que denota uma erudição espantosa - "[...] palavras já ditas / estas que vêm, lembradas, doutros poemas velhos" -, Sena apresenta o gesto escritural como uma aprendizagem de si próprio e do outro: "este papel, esta mesa, eu apreendendo o que escrevo".

Com o poema de Sena, estamos diante daquilo que Rosa Maria Martelo nomeou de uma "cena de escrita", imagem que aponta para uma teatralização do ato de escrever, ou melhor, imagem que se exibe ela própria como uma ceno-grafia. As cenas de escrita nunca são inocentes, diz a ensaísta, "elas indicam sempre uma poética e também uma ética da escrita" (2010, p.323). Repare-se pois que a base da poética do testemunho já está presente, ainda que em estado de latência, na "arte poética seniana que Os trabalhos e os dias exemplarmente traduzem" (2006, p.165), como bem mostrou Gilda Santos, e não foi por acaso que o livro Coroa da terra foi integrado posteriormente, por iniciativa do próprio Jorge de Sena, em Poesia I.

Da cenografia do poema seniano, quero viajar agora pelos mapas de Carlos de Oliveira, transitando por este mundo de palavras a que o poeta chamou cartografia:

\begin{tabular}{ll} 
MAPA & \multicolumn{1}{c}{ II } \\
\multicolumn{1}{c}{ I } & pensando \\
O poeta & que \\
[o cartógrafo?] & talvez alguma \\
observa & ave errante \\
as suas & traga \\
ilhas caligráficas & à solidão \\
cercadas & do mapa \\
por um mar & aos recifes desertos, \\
sem marés, & um frémito, \\
arquipélago & um voo, \\
a que falta & se for possível \\
vento, & voa \\
fauna, flora, & sobre tanta \\
e o hálito húmido & aridez. (1992, p.98) \\
da espuma, &
\end{tabular}

Integrante do conjunto de poemas que em 1968 Carlos de Oliveira publicara sob o título de Micropaisagem, o poema "Mapa" apresenta o poeta como o cartógrafo que "observa / as suas / ilhas caligráficas". Trata-se, claro está, de uma reflexão sobre as especificidades da linguagem, processo a que ele vinha submetendo a sua poesia desde a publicação de Cantata (1960), livro que a crítica especializada considera o ponto de transição da sua obra. Adepta num primeiro momento da poética neorrealista, a poesia de Carlos de Oliveira apresenta um percurso evolutivo que vai da preocupação social da escrita a um "crescendo para a autonomia do objeto estético" (Alves, 2000, p.124). Como assinala Manuel Gusmão, assistimos em sua 
poesia a uma passagem da voz à escrita ou, na proposta de leitura de Ida Alves, assistimos a um poeta que, de arauto, se faz artífice.

Aliás, todo o trabalho de revisão que durante anos Carlos de Oliveira veio empreendendo em seus versos permitem entrever em sua obra uma "depuração do excesso de dramatismo" (Alves, 2000, p.126), trabalho poético que coloca o seu leitor diante de uma economia da linguagem, de uma palavra enxuta que propositadamente se quer escassa mas densa de sentidos, como que a fazer eco aos famosos versos de João Cabral de Melo Neto em homenagem a Graciliano Ramos, artista que fez da depuração das palavras um processo "que as limpa do que não é faca: de toda uma crosta viscosa, / resto de janta abaianada" (1994, p.52).

Em "Mapa", Carlos de Oliveira apresenta-nos uma "paisagem cosmológica" (GUSMÃO, 2010, p.322) expressa em imagens que vão do macro ao micro. Com efeito, se levarmos em conta a tradição dos mapas, perceberemos que o termo cartografia é mais ou menos recente, datando de meados do século XIX. Durante um largo fosso temporal, o estudo do espaço geográfico recebia o nome genérico de Cosmografia, que abarcava abrangentemente a astronomia, a geografia e a ciência dos mapas. De fato, só no século XIX, tempo que compreende o ser humano e as suas diversas atividades a partir de coordenadas históricas muito precisas, é que o estudo da cartografia poderia surgir enquanto tal. Do latim charta (mapa/papel) e do grego graphien (escrita), a cartografia é, ao fim e ao cabo, a descrição do espaço no papel. Ao cotejarse ao cartógrafo, o sujeito poético de Carlos de Oliveira mapeia as suas ilhas-metáfora que são as palavras, "arquipélago / a que falta / o vento / fauna, flora" não apenas porque esse lugar é marcado por uma aridez tão típica do espaço poético que, no autor de Aprendiz de feiticeiro não raro coincide com a região da Gândara, mas talvez porque se configure (esse espaço-tempo) como um mundo assinalado por uma escassez ainda desejante do voo. Em outras palavras, por um mundo ainda passível de ser transformado.

Da exuberância discursiva de Jorge de Sena à poética da brevidade de Carlos de Oliveira, da cenografia seniana à cartografia oliveiriana, chegamos ao tempo da radicalização do conceito da autorreferencialidade da escrita com os poetas de Poesia 61. E o percurso aqui escolhido não é nada aleatório, já que Fiama nos ensina que "O progresso dos textos é epigráfico. Lápide e versão, indistintamente" (2006, p.173). A esse respeito, lembremos ainda que em sua raiz etimológica epígrafe significa escrever sobre, em cima de, tal qual um palimpsesto que traz no texto ulterior as marcas indeléveis do texto anterior. Jorge de Sena e Carlos de Oliveira são dois poetas de referência para as gerações futuras, e assim também para Fiama e seus contemporâneos, para os quais, sobretudo Carlos de Oliveira, é o poeta referencialmente nomeado de Mestre. De uma teatralização do ato de escrita representada numa ceno-grafia em Jorge de Sena passamos então ao apagamento do sujeito que se fossiliza ele próprio na paisagem de uma cartografia em prol da autonomia da linguagem, para chegarmos finalmente ao tempo da grafia, que não é outro senão o tempo de Poesia 61. 
"Grafia 1" é afinal o título do poema de abertura de Morfismos, conjunto de textos com o qual Fiama começa a inscrever-se na cena literária portuguesa:

\author{
GRAFIA 1 \\ Água significa ave \\ se \\ a sílaba é uma pedra álgida \\ sobre o equilíbrio dos olhos \\ se \\ as palavras são densas de sangue \\ e despem objectos \\ se \\ o tamanho deste vento é um triângulo na água \\ o tamanho da ave é um rio demorado \\ onde \\ as mãos derrubam arestas \\ a palavra principia (2006, p.15)
}

Emblemáticos, os versos "Água significa ave / se" tornaram-se definidores de toda a poética de Poesia 61, desejosa de uma desmontagem do poder pela e na palavra. Porque, cientes de que a língua é uma convenção e de que os signos são majoritariamente arbitrários, os poetas de Poesia 61 são também conscientes de que é apenas através da fricção, isto é, apenas através do corpo a corpo com a linguagem que a palavra se faz libertária. Talvez nenhuma outra geração como a que Fiama representou tenha sido mais consciente de que a língua é fascista e de que mudar a língua pode por vezes significar mudar o mundo. Ousaria mesmo dizer que o que Fiama empreende quase avant la lettre em Grafia 1 é aquela "trapaça salutar" que, só dezesseis anos mais tarde, em 1977, Roland Barthes definiria como um modo possível de romper com $o$ fascismo da língua (2007). Por outras palavras, Fiama trapaceia a língua, fazendo da sua poesia, como diz Jorge Fernandes da Silveira (2006/1986), uma poética que é sempre uma hipótese em curso, por recusar os sentidos cristalizados:

Por meio das suas próprias articulações, o princípio de equivalência entre "água" e "ave" ordena o poema no espaço interno de sua estrutura, sem pôr de lado, contudo, a possibilidade de se relacionar essa estrutura com a exterioridade dos conceitos estabelecidos.

Quer isto dizer: “Água significa ave”, se no poema se produzem coordenadas de uma "Grafia" que vão de encontro à conformidade dos significados fixos (água significa ave, água significa ave) e que propõem, na dissonância da coincidência produzida, o real modo fictício de estar no poema. A este processo denominamos textualização da palavra no poema. 
A partir da afirmação de que existe uma tese em desenvolvimento, as estrofes encabeçadas por "se" configuram-se fulcro de antítese, se comparadas a uma prática convencional de versificação [...] (SILVEIRA, 1986, p.67, grifo do autor).

“Onde / as mãos derrubam arestas / a palavra principia", estes os versos finais de "Grafia 1", configurando-se como palavras extremamente pertinentes, se considerarmos a sua referencialidade histórica. Derrubando arestas, diga-se, os convencionalismos de linguagem, os poetas de Poesia 61 revolucionaram a língua sem contudo deixar de ler a ambiência espácio-temporal que os circundava. "[...] Posso dizer que o poeta imorredouro / é o que introduz na língua a metáfora mais densa" (2010, p.46), assinala Fiama, sem nunca abdicar de assinalar também: "a minha existência (entre os iberos) urge" (2010, p.30).

\section{Referências}

ALVES, Ida. Carlos de Oliveira e Nuno Júdice poetas: personagens da linguagem. Tese de Doutorado em Letras Vernáculas. Rio de Janeiro: UFRJ, 2000.

BARTHES, Roland. Aula. Trad. Leyla Perrone-Moisés. São Paulo: Cultrix, 2007.

BARTHES, Roland. O grau zero da escrita. Trad. Mario Laranjeira. São Paulo: Martins Fontes, 2000.

BRANDÃO, Fiama Hasse Pais. Âmago: antologia. Lisboa: Assírio \& Alvim, 2010.

BRANDÃO, Fiama Hasse Pais. Obra breve. Lisboa: Assírio \& Alvim, 2006.

GUSMÃO, Manuel. A arte da poesia em Carlos de Oliveira. In: Tatuagem \& palimpsesto: da poesia em alguns poetas e poemas. Lisboa: Assírio \& Alvim, 2010, p.315-338.

MARTELO, Rosa Maria. Cenas de escrita (alguns exemplos). In: A forma informe: leituras de poesia. Lisboa: Assírio \& Alvim, 2010, p.321-343.

NETO, João Cabral de Melo. Obra completa. Rio de Janeiro: Nova Aguilar, 1994.

OLIVEIRA, Carlos de. Micropaisagem. Lisboa: Caminho, 1992.

PAZ, Octavio. O arco e a lira. Trad. Ari Roitman \& Paulina Wacht. São Paulo: Cosac Naify, 2012.

SANTOS, Gilda. Jorge de Sena: "Quarenta anos de pública servidão poética". In: Jorge de Sena: ressonâncias e cinquenta poemas. Introdução e organização de Gilda Santos. Rio de Jameiro: 7 Letras, 2006. 
SENA, Jorge de. Poesia I. Lisboa: Edições 70, 1977.

SILVEIRA, Jorge Fernandes da. Lápide \& Versão: ensaios sobre Fiama Hasse Pais Brandão. Rio de Janeiro: Bruxedo, 2006.

SILVEIRA, Jorge Fernandes da. Portugal Maio de Poesia 61. Vila da Maia: Imprensa Nacional - Casa da Moeda, 1986. 